\title{
A Feasibility Study of Heat Pipes for Thermal Management of Electrical Machines
}

\author{
Rafal Wrobel, David Reay \\ School of Engineering, Newcastle University, Newcastle upon Tyne, UK \\ rafal.wrobel@newcastle.ac.uk
}

\begin{abstract}
This theoretical feasibility study explores the use of heat pipes (HPs) in thermal management of electrical machines. The research focus has been placed on the statorwinding assembly to assess suitability and effectiveness of HPbased heat removal systems. The proposed approach targets the main heat source in electrical machines, which frequently is associated with the winding subassembly. Two generic concept thermal management systems are investigated. The first one uses HPs to enhance heat removal for a machine with conventional cooling, e.g. a liquid or air-cooled housing. The second concept uses HPs as the main heat transfer path, e.g. a fully enclosed machine with no integrated, actively cooled housing. The electromagnetic and thermal compatibility of the proposed HP-based thermal management systems is analysed by means of three-dimensional (3D) finite element analyses (FEAs). The theoretical findings show that the proposed thermal management systems allow for a considerable improvement in heat removal from the machine body, up to $43 \%$ and $25 \%$ for the concept one and two respectively, as compared with a more conventional heat removal system. The overall performance gains are subject to the specific manufacture and assembly processes used in construction of the stator-winding.
\end{abstract}

Keywords-thermal management system, heat transport, heat pipes, electrical machines, motorette testing, power loss analysis

\section{INTRODUCTION}

Heat pipe (HP) technology has been developing for well over a century. The predecessor of a modern-day HP is the Perkins tube introduced in 1831, which was later developed from a single- to two-phase-cycle system, 1836, with the early applications including bread-baking ovens and locomotive fire box super-heaters [1]. Over the years of development HPs have been successfully implemented in numerous applications, with broad groups including, separation of heat source and heat sink, temperature flattening or isothermalisation, heat flux transformation, temperature control, thermal diodes and thermal switches [1], [2]. The history of application of HPs in thermal management of electrical machines spans several decades and fits within the temperature flattening and control themes, with numerous research papers, reports and patents documenting the technology evolution [1]-[23]. When reviewing the literature, it is evident that almost all possible/generic concepts of employing HPs in thermal management of electrical machines, both for stator and rotor subassemblies have been previously considered [11], [15], [16]. Some of the concepts include HP rotor shaft cooling, HP stator or winding cooling and HPs as a squirrel cage and cooling feature for an induction machine, among others [16].

Although, it might seem that the subject of HPs in electrical machines has already been well explored [1]-[21], the existing literature lays only a groundwork. Further application driven research is required to fully understand potential benefits of the HP-based or -enhanced thermal

This work was supported in by the Engineering and Physical Sciences Research Council (EPSRC) UK (Future Electrical Machines Manufacturing Hub, EP/S018034/1). management approach. This together with the dynamic drive towards new electrified solutions for demanding automotive and aerospace applications leads to the conclusion that the subject of thermal management of electrical machines using HPs is worth revisiting. The latest evolutions of the electrical machine and HP technologies, such as the introduction of new manufacturing techniques (additive manufacturing (AM)) or new materials (new metal alloys, ceramics or polymerase) are some of the interesting prospects for integrating new HP concepts for effective and reliable heat removal in electrical machines [5]-[7]. It is worth mentioning that HPs can be designed to have a form and performance tailored to a specific application, e.g. the use of an appropriate metal alloy, working fluid and wick structure sets the HP's operating temperature range and overall performance (high heat flux or high mass flow design) [1], [2].

This feasibility study was initially aiming to evaluate theoretically and experimentally the use of HPs in thermal management of electrical machines. However, due to the COVID-19 lockdown the authors were unable to sufficiently progress the experimental body of work to supplement the theoretical investigation discussed in this paper. The proposed HP-based heat removal approach targets the stator-winding subassembly, which frequently represents the main heat source in electrical machines. Two generic concept thermal management systems are investigated. The first one uses HPs to enhance heat removal for a machine with conventional, active cooling, e.g. a liquid or air-cooled housing. The second concept uses HPs as the main heat transfer path, e.g. a fully enclosed machine with no integrated, actively cooled housing. The main challenges associated with incorporating HPs for heat removal from electrical windings are associated with the electromagnetic and thermal compatibility of these two subassemblies. The additional power loss introduced by the HP assembly exposed to the winding, slot flux leakage and thermal contacts between the heat source, heat transport and heat sink parts need to be carefully considered. Some of these aspects were discussed in the authors' previous work on metallic heat guides (HGs) for enhanced heat transfer in electrical machines [21]. In this paper a comprehensive analysis of additional HP power losses together with heat transport is presented. Here, the theoretical findings show that HP-based thermal management of electrical machines offers considerable performance benefits, e.g. up to $17 \%$ and $2 \%$ increase in specific output (torque/power) as compared with a more conventional machine build.

\section{HEAT PIPES - CONSTRUCTION AND PRINCIPLES OF OPERATION}

A conventional wicked HP consists of a sealed container, in which a wick is placed on the inner radius of the pipe wall, as shown in Fig. 1. The wick acts as a capillary pump, which returns the condensate to the evaporator section of the HP. There are several types of wicks, which provide different performance and cost measures. E.g. grooved HPs offer the 


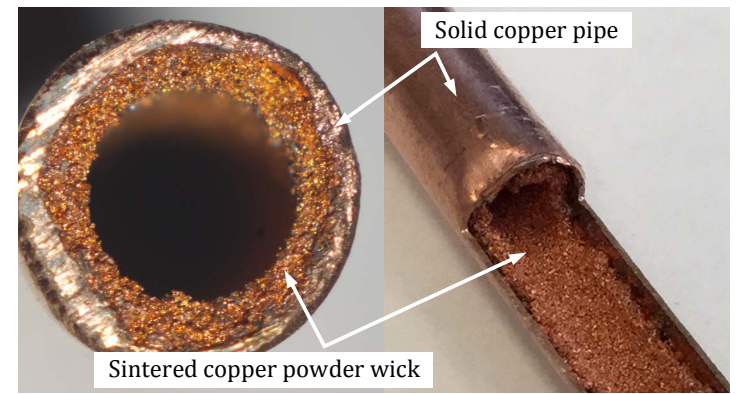

Fig. 1. Construction of a copper-water HP with copper powder sintered wick - European Thermodynamics Ltd. [22].

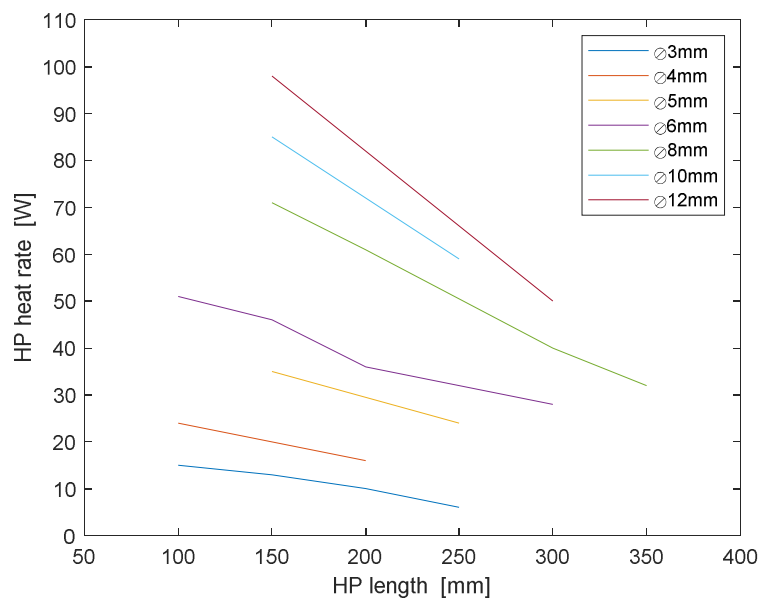

Fig. 2. Heat rate of heat transport for alternative length and outer diameter of sintered copper-water HP - European Thermodynamics Ltd. [22].

lowest cost and performance, but are not ideal for liquid return against gravity, whereas sintered HPs have the highest cost and performance, with good pumping capability [1], [2]. The meshed HPs provide a compromise between the grooved and sintered HP variants. For a given HP construction, a sufficient amount of working fluid is introduced into the sealed pipe to saturate the wick with liquid. When heat is introduced to the evaporator section of the HP, liquid placed in the wick evaporates over that portion of the HP body. The vapor then enters the vapor space and travels towards the condenser as a result of a pressure difference between the evaporator and condenser (higher pressure at the evaporate end of HP). Removing heat from the condenser causes condensation of the vapor, which releases its latent heat. The condensate is then pumped back to the evaporator due to the capillary-force, which is generated at the liquid-vapor interfaces of the wick pores.

The phase-change phenomena employed in HPs allows one to achieve very high values of equivalent thermal conductivity up to $100,000 \mathrm{~W} / \mathrm{m} \cdot{ }^{\circ} \mathrm{C}$ [22], [23], as compared with pure copper, $387 \mathrm{~W} / \mathrm{m} \cdot{ }^{\circ} \mathrm{C}$. This value depends upon the mechanisms used to add heat at the evaporator, and remove it at the condenser, of course, where high thermal resistances may exist. Particular types of HP, such as loop types or gravity-assisted thermosyphons, are well suited for transferring heat over long distances with a low temperature drop, providing an approximately isothermal surface for temperature flattening or controlling. This is very attractive in the context of thermal management of electrical machines, where the generated heat needs to be removed from intricate composite structures, e.g. winding body or rotor assembly. Note that in this investigation off the shelf copper- a)

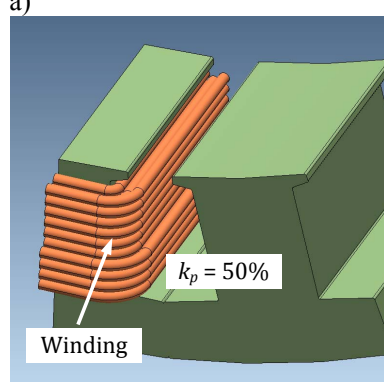

b)

Fig. 3. Outline of the stator-winding assembly, a) baseline design $k_{p}=$ $50 \%$, b) alternative design to accommodate for HP-based thermal management system $k_{p}=38 \%$.

water HPs with a sintered wick are considered, $(\mathrm{Cu} \mathrm{C} 1020$, de-ionised water). Fig. 2 presents heat transfer capability for the HP family used in this analysis. It is evident that both HP length and active cross section have significant impact on the overall heat transport capability.

\section{CASE STUDY}

\section{A. Stator-Winding Construction}

Fig. 3 presents a 3D model representation of a portion of the analysed stator-winding assembly, which is representative of a permanent magnet (PM) machine (rated power, $80 \mathrm{~kW}$ and rated rotational speed, 8000rpm [21]. It is assumed here that the stator is laminated using electrical steel (M250-35A), and the double-layer concentrated winding uses round copper conductors with class $\mathrm{H}\left(180^{\circ} \mathrm{C}\right)$ enamel coating. Note that a precision wound winding with a single conductor per turn is assumed here for a repeatable manufacturing process. A slot liner material (PEEK-based Aptive1000) is used to provide an electrical separation between the stator core pack and conductors, and HG and conductors. The complete stator-winding assembly is vacuum impregnated using high thermal conductivity epoxy resin (Epoxylite EIP4260) to assure good heat transfer from the winding body to a heatsink, e.g. actively cooled machine housing. The analysed HPs are integrated together with the heat guiding, $\mathrm{HG}$, portion of the overall assembly. To provide a fair comparison between the conventional and HP-based thermal management system, the baseline stator-winding assembly fully utilises the slot window, with $50 \%$ conductor fill factor $\left(k_{p}\right)$, Fig. 3a). In contrast, winding fill factor for HPbased heat removal is reduced to $38 \%$ to accommodate for the supplementary heat transfer path, Fig. 3b). Note that the number of turns per coil remains the same for both windings, and the conductor fill factor is altered by adjusting the conductor diameter.

\section{B. Thermal Model-Assumptions}

The alternative thermal management systems considered in this investigation are schematically shown in Fig. 4. A 3D FE approach is used here to account for the conductive and convective heat transfer mechanisms in the stator-winding assembly. The convective heat transfer from the motor housing or HPs periphery is emulated by appropriate boundary conditions, e.g. fixed temperature of $60^{\circ} \mathrm{C}$ for active heat removal or pre-set convective heat transfer coefficient of $25 \mathrm{~W} / \mathrm{m}^{2} \cdot{ }^{\circ} \mathrm{C}$ for natural convection, Fig. 4. Two concept thermal management systems are considered, system-I (S-I) where both machine housing and HPs are actively cooled and system-II (S-II) where HPs are actively cooled, and the motor housing is naturally ventilated. The remaining outer surfaces 
a)

b)
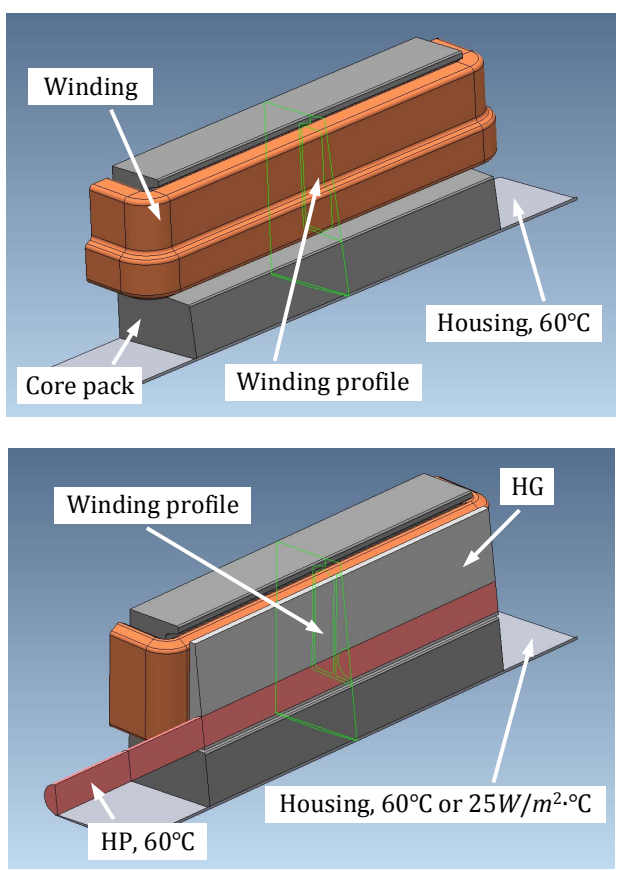

Fig. 4. 3D FE thermal model representation of alternative thermal management systems, a) baseline model with actively cooled housing, b) proposed HP-based thermal management system for enhanced (S-I) or primary (S-II) heat removal.

TABLE I. MATERIAL THERMAL DATA

\begin{tabular}{lc}
\hline & Thermal conductivity $\left[\mathrm{W} / \mathrm{m} \cdot{ }^{\circ} \mathrm{C}\right]$ \\
Model region & $k_{x}=k_{y}=2.5, k_{z}=188.7$ \\
Winding ${ }^{1)}$ & $k_{x}=k_{y}=2.3, k_{z}=172.3$ \\
Winding $^{2}$ & $k_{x}=k_{y}=24.5, k_{z}=5.8$ \\
Core pack & $k_{x}=k_{y}=175, k_{z}=34.5$ \\
$\mathrm{HG}$ & $k_{x}=k_{y}=k_{z}=230$ \\
$\mathrm{HP}^{3)}$ & $k_{x}=k_{y}=14, k_{z}=8000$ \\
$\mathrm{HP}^{4)}$ & $k_{x}=k_{y}=14, k_{z}=30000$ \\
$\mathrm{HP}^{5)}$ & $k_{x}=k_{y}=k_{z}=0.85$ \\
Epoxy resin & $k_{x}=k_{y}=k_{z}=0.25$ \\
Slot liner & Contact interface ${ }^{6)}[\mu \mathrm{m}]$ \\
& \\
Model interface & 10 \\
Core pack to winding & 0 to 100 \\
Winding to HG & 0 to 100 \\
HG to HP & 10 \\
Core pack to housing &
\end{tabular}

1) Baseline winding design, $k_{p}=50 \%$.

2) Alternative winding design, $k_{p}=38 \%$.

${ }^{3)} \mathrm{HP}$ variant I (HP-VI) equivalent to HG made of solid aluminium.

4) HP variant II (HP-VII).

5) HP variant III (HP-VIII).

${ }^{6)}$ Equivalent air-gap emulating thermal contact interface.

of the model are assumed to have a negligible contribution to the overall heat transfer, i.e. defined with an adiabatic boundary condition. All composite stator-winding subassemblies like the impregnated winding, stator core pack, HG and HP are modelled using the equivalent thermal properties. Table I provides a complete list of material properties used in the thermal FEAs. Note that the epoxy resin encapsulating the winding body is not shown in Fig. 4 for better clarity. To provide a more comprehensive insight into the heat transfer effects, a sensitivity analysis of the thermal contact interfaces and HP equivalent thermal conductivity is carried out for the analysed thermal management systems. The contact thermal interfaces listed in Table I are modelled as an equivalent air-gap defined with a thin-layer boundary condition. Such a model definition allows to significantly simplify the model geometry, i.e. no need for contact regions with small geometrical dimensions, where appropriate [21].

Further to these, an ideal model representation of the HP is assumed in this analysis, i.e. fixed equivalent thermal conductivity, which is independent of the HP's operating point. The equivalent thermal conductivity across the HP body has been derived based on physical properties of the HP constituent materials and geometrical dimensions. In contrast, the equivalent thermal conductivity along the HP length has been assumed based on the available literature [1], [23]. Note that HP-VI in Table I is equivalent to a HG made of solid aluminium, which is similar to that analysed by the authors in their previous work [21]. To provide a good thermal path between the winding and HP, a HG subassembly made of stacked, pre-bonded aluminium-nitride (AIN) substrate was used here, Fig. 4a). Note that the HG material has relatively high thermal conductivity of $180 \mathrm{~W} / \mathrm{m} \cdot{ }^{\circ} \mathrm{C}$, as for ceramics, and does not introduce any additional power losses, which have been shown to be significant for solid metallic HGs [21]. The integrated HP/HG assembly analysed in this investigation allows for the heat to be transported directly from the winding body to a heat exchanger, e.g. a liquid cooled heat exchanger integrated with one of the machine endcaps.

\section{Electromagnetic Model-Assumtions}

The initial thermal analysis discussed in this paper is representative of hardware testing with dc winding excitation. Such a method is commonly used in thermal characterisation of electrical machines, as it allows for relatively simple identification of the key heat transfer parameters associated with the winding assembly. Note that the static thermal testing is illustrative of low-speed electrical machine operation, i.e. dc winding power loss is the dominant component. However, when analysing electrical machines, where the stator-winding ac effects are non-negligible, a more detailed approach is needed. In this investigation, the fundamental operating frequency is approximately $1 \mathrm{kHz}$. Also, the magnetic loading, $B_{1}$, assumed here is equal to $1.0 T$ (with sinusoidal variation of the air-gap magnetic flux density). Consequently, both excitation and rotational ac winding effects are expected to have a considerable impact on the overall winding power loss. As the analysed winding variants have different construction, Fig. 3, it is expected that the ac power losses will have a prominent impact on findings from the initial thermal investigation, details of which are presented in the next section of the paper.

Further to these, the additional power loss component associated with HP assembly is analysed. As the exact

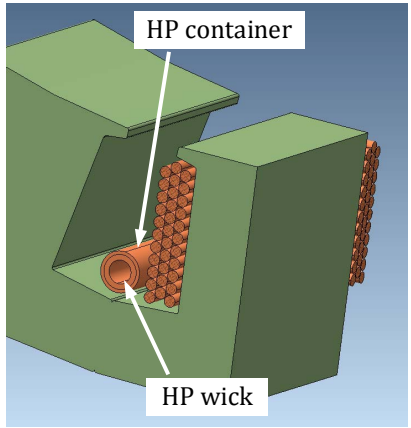

Fig. 5. 3D FE electromagnetic model representation of the HP assembly 
a)

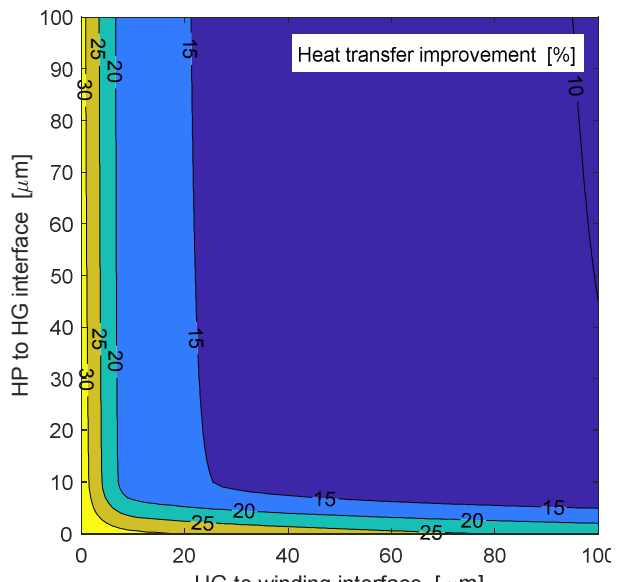

b)

c)
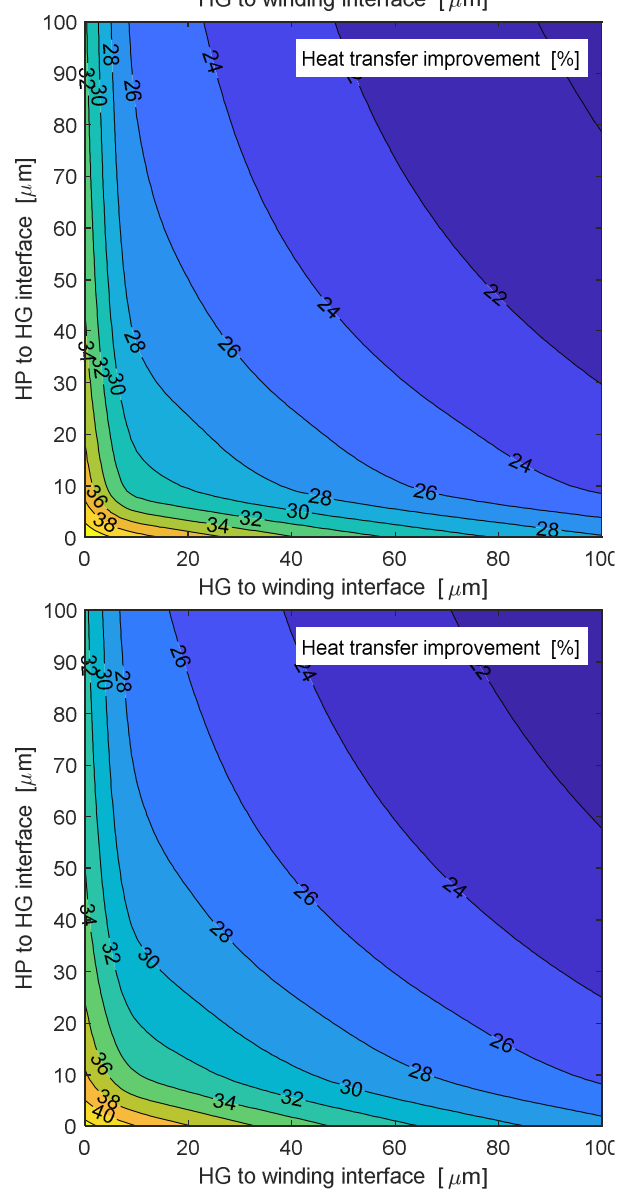

d)

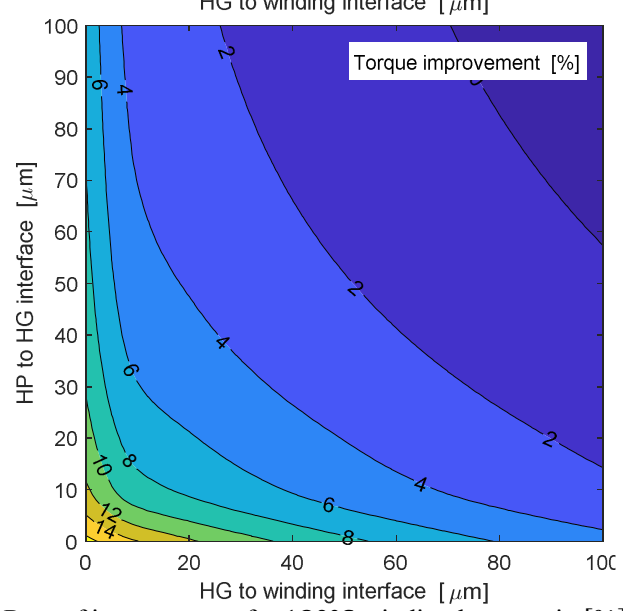

Fig. 6. Rate of improvement for $180^{\circ} \mathrm{C}$ winding hot-spot in [\%], for SI with both machine housing and HPs being actively cooled at $60^{\circ} \mathrm{C}$, a) heat transfer for HP-VI, b) heat transfer for HP-VII c) heat transfer for HP-VIII, d) output torque for HP-VIII. a)

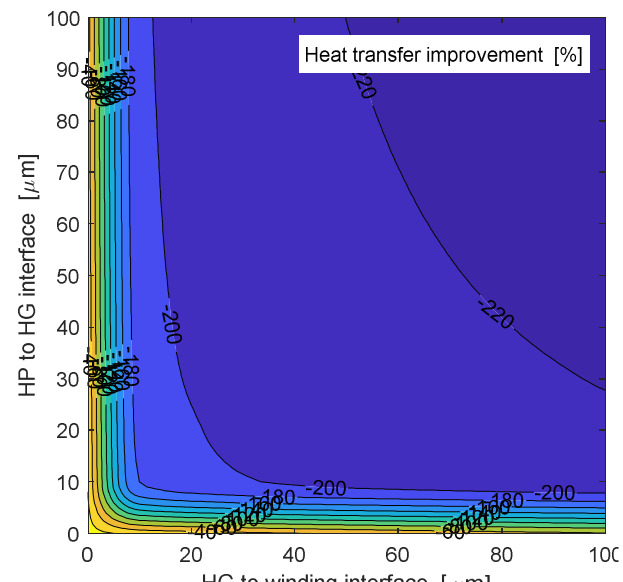

b)

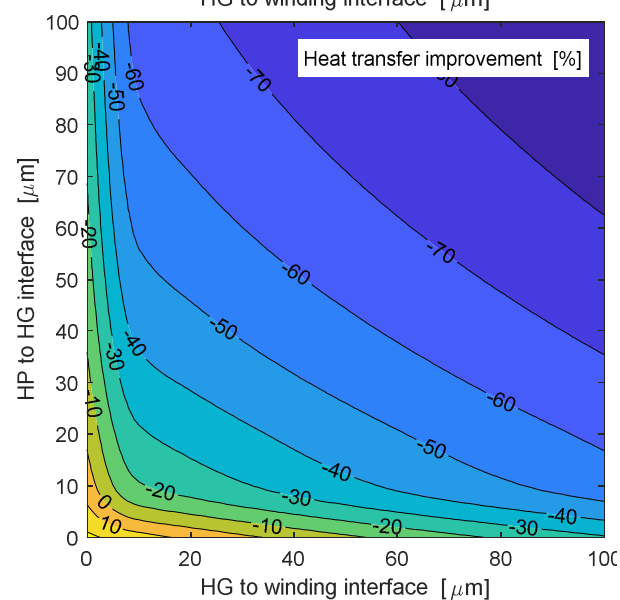

c)

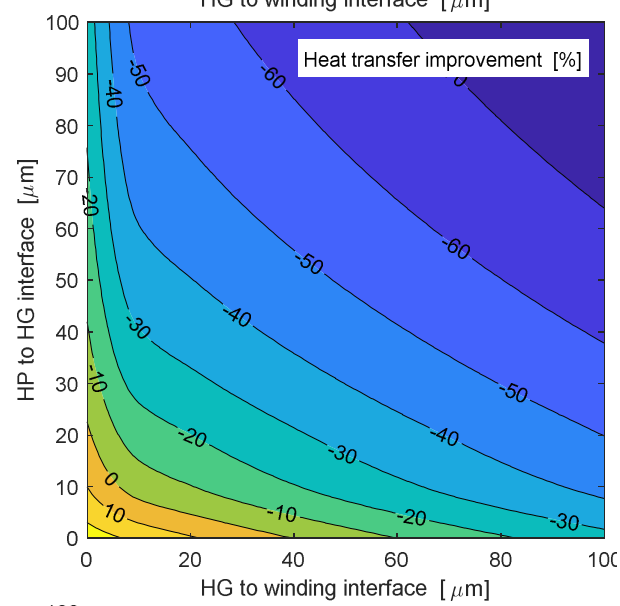

d)

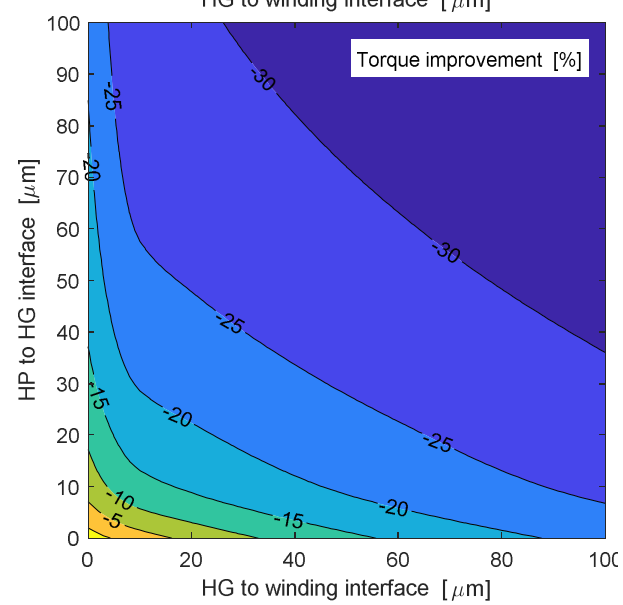

Fig. 7. Rate of improvement for $180^{\circ} \mathrm{C}$ winding hot-spot in [\%], for SII with HPs being actively cooled at $60^{\circ} \mathrm{C}$ and motor housing naturally cooled at $25 \mathrm{~W} / \mathrm{m}^{2} \cdot{ }^{\circ} \mathrm{C}$, a) heat transfer for HP-VI, b) heat transfer for HP-VII c) heat transfer for HP-VIII, d) output torque for HP-VIII. 


\begin{tabular}{ll}
\multicolumn{1}{c}{ TABLE II. } & HP BASIC DATA \\
\hline Outer diameter $[\mathrm{mm}]$ & 6 \\
Length $[\mathrm{mm}]$ & 150 \\
Wall thickness $[\mathrm{mm}]$ & 0.5 \\
Wall electrical resistivity $[\Omega \mathrm{m}]$ & $1.7241 \cdot 10^{-8}$ at $20^{\circ} \mathrm{C}$ \\
Wick thickness $[\mathrm{mm}]$ & 0.8 \\
Wick electrical resistivity $[\Omega \mathrm{m}]$ & $3.4482 \cdot 10^{-8}$ at $20^{\circ} \mathrm{C}$ \\
Wick porosity & $50 \%$ \\
\hline
\end{tabular}

electromagnetic model representation of sintered HP structure is not feasible, a simplified approach has been employed here. Both solid copper container and wick parts are accounted for. The wick structure is represented as a homogeneous region with the equivalent electrical resistivity of solid copper increased by factor of two, Fig. 5 . This is due to $50 \%$ porosity of the wick structure. The effect of de-ionised water or water vapor on the power loss predictions has been neglected in this investigation and will be assessed experimentally at a later stage of the research. Fig. 5 shows a 3D model representation of the analysed sintered copper HP, and Table II list the HP basic data assumed in the analysis. Note that HG subassembly is not included in the FE model due to negligible power loss associated with AlN material, i.e. high electrical resistivity $1.014 \cdot 10^{1} \Omega \mathrm{m}$. Also, the initial results have shown that a $2 \mathrm{D}$ FE model is sufficient when analysing power losses associated with the HP.

\section{RESULTS AND DISCUSSION}

\section{A. Heat Transfer Analysis}

Figs. 6 and 7 present results from the thermal sensitivity analysis for both thermal management systems considered in this investigation, S-I and S-II. As a reference, the baseline stator-winding design is used. The percentage rate of improvement in heat removal for $180^{\circ} \mathrm{C}$ hot-spot winding temperature shown in Figs. 6 and 7 has been calculated here using an equivalent thermal resistance between the winding hot-spot and heat sink at $60^{\circ} \mathrm{C}$. Such a definition allows for all analysed heat transfer mechanisms to be accounted for in a single parameter. When comparing impact of the contact thermal interface between the HG and winding, and HP and $\mathrm{HG}$, it is evident that both paraments have a significant effect on the overall heat removal. The theoretical predictions suggest that the HP-based thermal management system with high equivalent axial thermal conductivity, e.g. HP-VIII, is less sensitive to the manufacture imperfections. The manufacture imperfections have a similar/detrimental effect for both analysed thermal management systems. Also, it is evident that S-II is less effective when comparing the overall performance gains.

\begin{tabular}{|c|c|c|c|}
\hline TABLE & \multicolumn{3}{|c|}{ MAXIMUM RATE OF IMPROVEMENT DATA } \\
\hline \multirow{2}{*}{ Design variant } & \multicolumn{3}{|l|}{ S-I } \\
\hline & {$[\%]^{1)}$} & {$[\%]^{2)}$} & {$\left[A / \mathrm{mm}^{2}\right]^{3)}$} \\
\hline HP-VI & 34 & 9 & 22 \\
\hline HP-VII & 41 & 15 & 23 \\
\hline HP-VIII & 43 & 17 & 24 \\
\hline \multirow{2}{*}{ Design variant } & S-II & & \\
\hline & {$[\%]^{1)}$} & {$[\%]^{2)}$} & {$\left[A / \mathrm{mm}^{2}\right]^{3)}$} \\
\hline HP-VI & -11 & -16 & 17 \\
\hline HP-VII & 22 & 0 & 20 \\
\hline HP-VIII & 25 & 2 & 21 \\
\hline
\end{tabular}

\footnotetext{
1) Rate of improvement in heat removal.

2) Rate of improvement in output torque at low speed operation.

3) Dc current density rating at low speed operation.
}

Figs. 6d) and 7d) show improvement in the machine output torque for HP-VIII. It has been assumed here that the machine operates at low speed. The calculated results show up to $17 \%$ increase in output torque for S-I and $2 \%$ for S-II. Table III summarises the maximum rate of improvement for all analysed cases. Note that the negative data values in Table II indicate reduction in performance as compared with the reference machine design. Table II also lists dc conductor current density. It is shown here that current densities up to $24 \mathrm{~A} / \mathrm{mm}^{2}$ (HP-VIII) can be sustained continuously at low speed operation. In contrast, the baseline machine design is capable of operating with $15 \mathrm{~A} / \mathrm{mm}^{2}$. If the active motor housing water cooling was to be replaced with a naturally ventilated alternative $\left(25 \mathrm{~W} / \mathrm{m}^{2} \cdot{ }^{\circ} \mathrm{C}\right)$, only $6 \mathrm{~A} / \mathrm{mm}^{2}$ is achievable.

\section{B. Power Loss Analysis}

To provide more insight into the overall performance gains associated with the use of the proposed HP-based thermal management concepts, a detailed power loss analysis has been carried out. Fig. 8 presents ratio of the winding power loss at ac operation to dc power loss, $P_{a c} / P_{d c}$, derived at rated current and fixed temperature. When analysing the results, it is evident that the high-speed operation has a significant impact on the winding power loss. Here, the baseline winding design, $k_{p}=50 \%$, exhibits up to four times increase of the winding equivalent resistance at full speed, 8000rpm $(\sim 1 \mathrm{kHz})$. In contrast, the winding variant with reduced conductor fill factor, which was introduced to accommodate for the $\mathrm{HP} / \mathrm{HG}$ assembly, has less prominent ac winding power losses. This difference is expected to have an important effect on the thermal behaviour and specific output capabilities of the analysed electrical machine variants, details of which are discussed further in the text.

Fig. 9 shows additional power loss introduced by the HP assembly exposed to the winding, slot magnetic flux leakage. Here, the HP power loss is referred to the winding dc loss. The results show that the additional HP power loss is approximately $5 \%$ of dc winding power loss when operating at elevated temperature, $200^{\circ} \mathrm{C}$. For completeness, the HP power loss is compared with that generated in the $\mathrm{HG}$ equivalent made of solid aluminium, Table I. The power loss predictions suggest that HP-based solution offers here better thermal performance and comparable power loss as for the HG alternative.

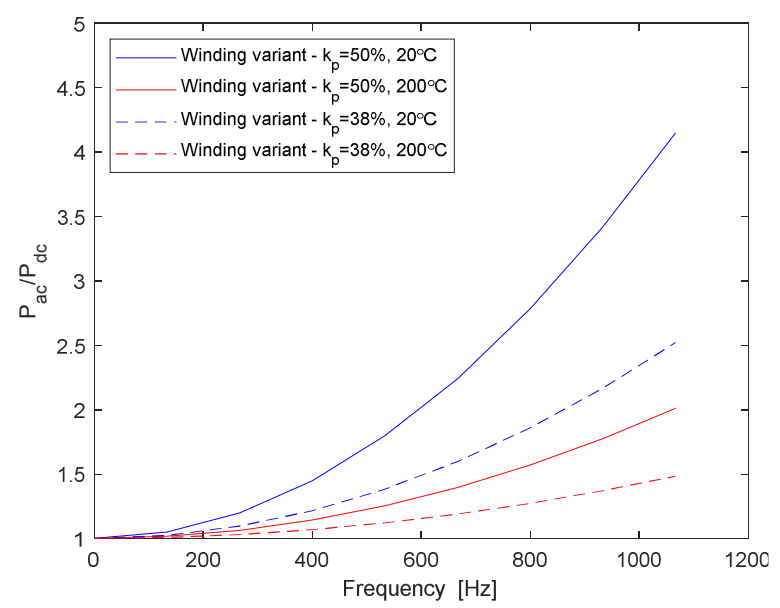

Fig. 8. Winding power loss ratio, $P_{a c} / P_{d c}$ versus excitation frequency for windings active length at rated current. 


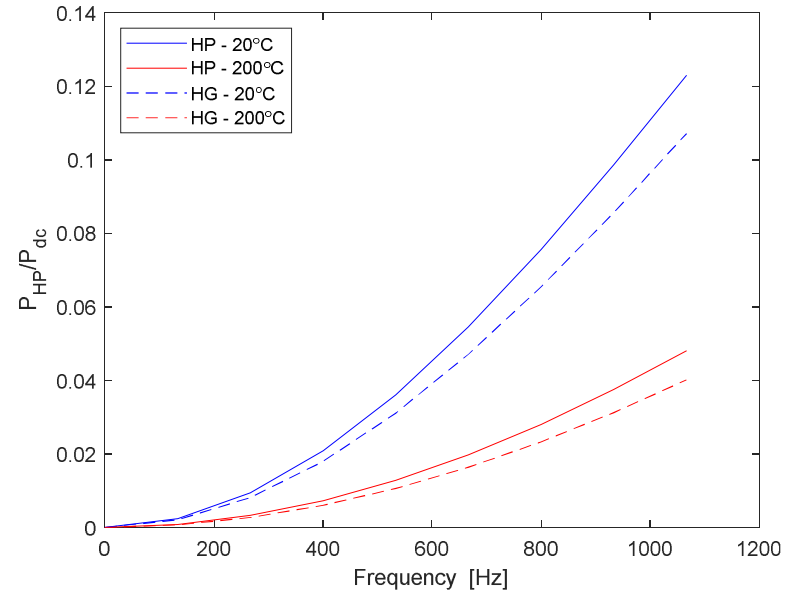

Fig. 9. HP additional power loss ratio versus excitation frequency.

a)

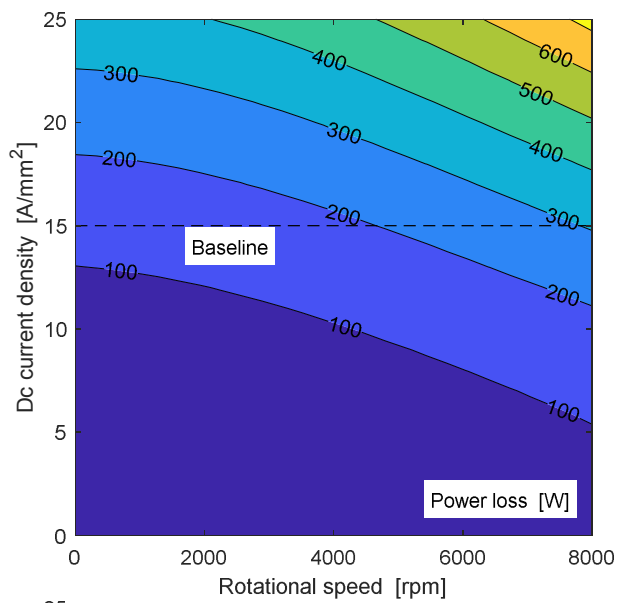

b)

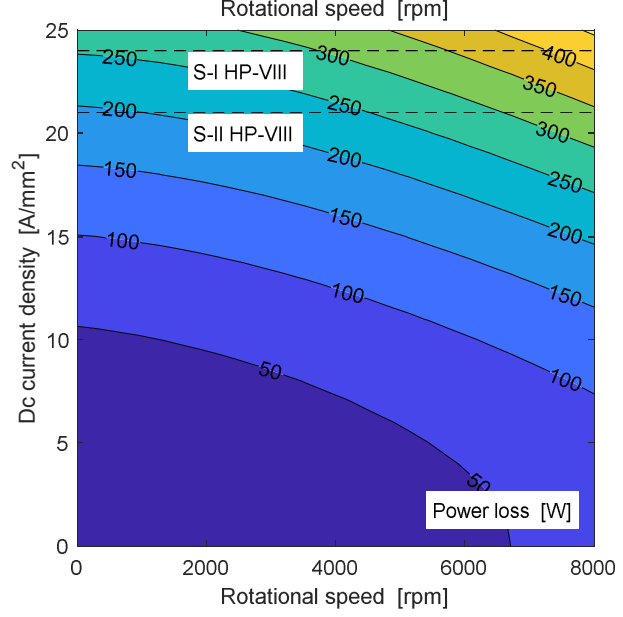

Fig. 10. Combined stator-winding power loss at ac operation at $180^{\circ} \mathrm{C}$ versus rotational speed and dc current density, a) baseline winding construction with $k_{p}=50 \%$, b) alternative winding construction with $k_{p}=38 \%$.

To provide a more detailed view of the ac effects, a combined stator-winding power loss has been mapped for a given range of dc winding current density and rotational speed, Fig. 10. Note, that the analysis assumes maximum torque per Ampere operation to illustrate severity of the ac effects. Also, power loss per single stator-winding segment is shown in Fig. 10. As the analysed winding variants have different conductor cross-sections (fill factor), the overall stator-winding power loss is higher for the baseline winding design. This is due to higher conductor volume for a given conductor dc current density. When comparing dc current densities indicated for selected design variants, i.e. baseline, S-I HP-VIII and S-II HP-VIII, it is evident that the ac power loss components lead to reduced specific output of the machine, i.e. reduced dc current density when following a power loss contour with increased speed. Note that the power loss maps in Fig. 10 have been derived for a fixed winding temperature equal to $180^{\circ} \mathrm{C}$.

\section{Motor Thermal Envelope}

This section presents thermal envelopes for alternative thermal management systems investigated in this analysis. It has been assumed here that the equivalent air-gap emulating

a)

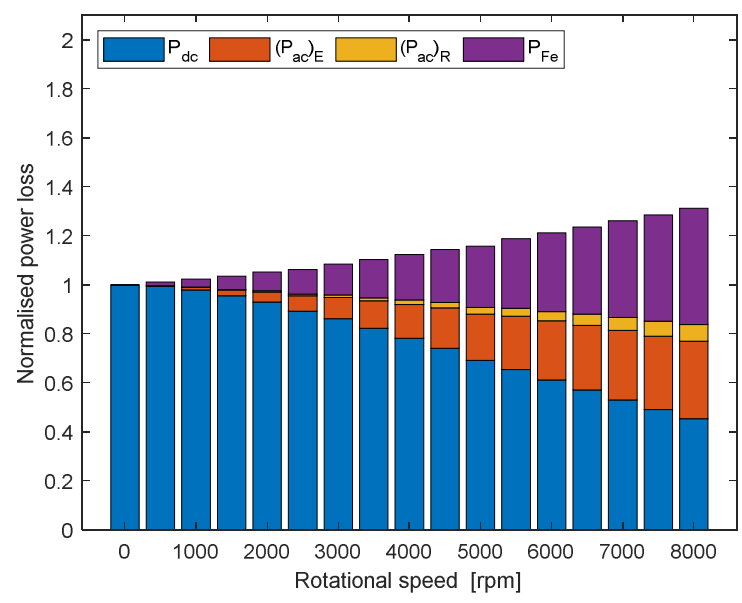

b)

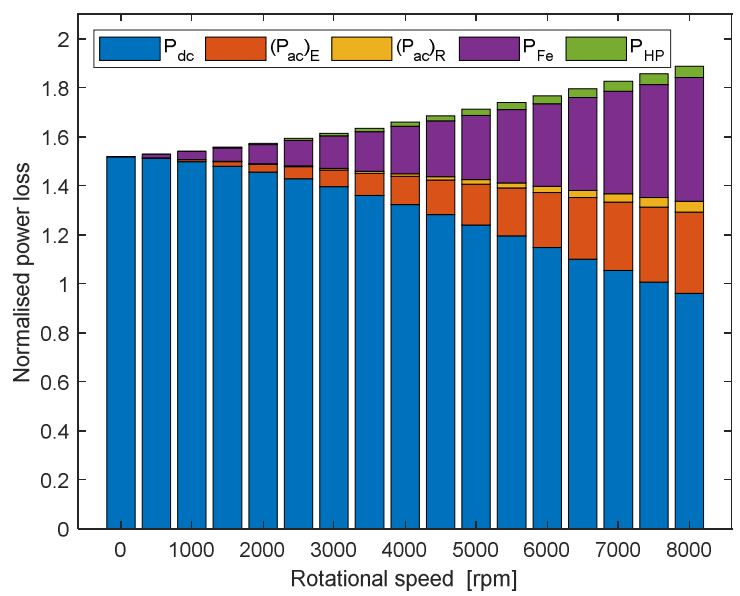

c)

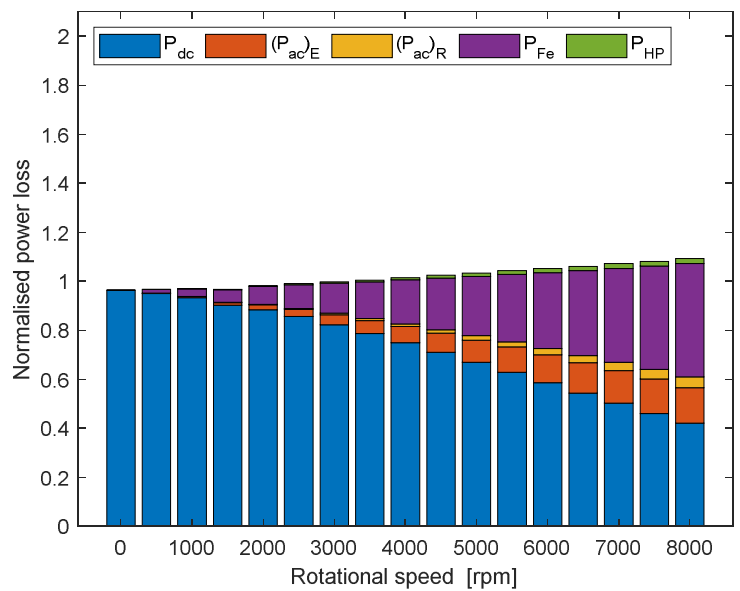

Fig. 11. Normalised power loss data for $180^{\circ} \mathrm{C}$ temperature limit, for alterative thermal management systems, a) baseline, b) S-I HP-VIII, c) SII HP_VIII, with $10 \mu m$ winding to HG and HG to HP equivalent air-gap. 
imperfections in thermal contact between winding and $\mathrm{HG}$ and $\mathrm{HG}$ and $\mathrm{HP}$ is equal to $10 \mu \mathrm{m}$. The remaining contact thermal resistances are as listed in Table I. Fig. 11 presents the normalised power loss envelope for $180^{\circ} \mathrm{C}$ temperature limit, for the baseline, S-I HP-VIII and S-II HP thermal management variants. Note that the temperature limit is associated with the class of electrical insulation (class $\mathrm{H}$ ) of the winding. The total power loss analysed here includes,

$$
P_{a c}=P_{d c}+\left(P_{a c}\right)_{E}+\left(P_{a c}\right)_{R}+P_{F e}+P_{H P},
$$

where: $P_{a c}$ is the dc winding power loss, $\left(P_{a c}\right)_{E}$ is the ac winding power loss from excitation, $\left(P_{a c}\right)_{R}$ is the winding ac power loss from rotation, $P_{F e}$ is the stator core power loss and $P_{H P}$ is the HP power loss.

The power loss data in Fig. 11 has been normalised to dc winding power loss at zero-speed for the baseline case. When analysing the results, it is evident that the excitation power loss components in the winding and stator core have a significant impact on the current handling (output torque/power). The results suggest that S-I HP-VIII is capable of removing up to $43 \%$ more dc power losses at low-speed operation and almost the same dc winding power loss at fullspeed as the baseline system at zero-speed. In contrast, S-II HP-VIII has lower power handling capability as compared with the reference system. However, the system offers reduced winding ac power losses and possibly reduced overall weight of the mechanical/ thermal management system. Note that the high-speed performance will be affected by introduction of a specific field weakening regime, i.e. a reduced stator-winding power loss is expected [24]. In this initial analysis specifics of the electric motor drive are not investigated, but similar performance gains are anticipated when introducing a specific operating envelope.

Although, the increase in heat removal by introducing HPbased thermal management systems has been shown, gains related to the machine output torque/power are yet to be discussed. Fig. 12 presents normalised output torque envelope for the thermal management systems discussed in the previous section. The results show that S-I HP-VIII offers approximately $10 \%$ and $30 \%$ increase in the output torque at zero- and full-speed operation respectively. On the other hand, S-II HP-VIII reduced torque output by $15 \%$ over the entire speed range. This lower than initially anticipated machine performance improvements are associated with the contact

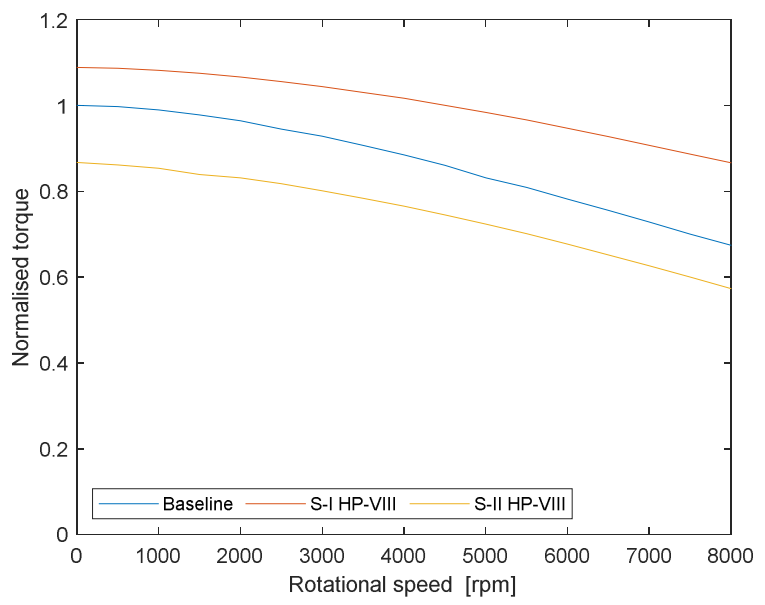

Fig. 12. Output torque envelpe vesus rotational speed for $180^{\circ} \mathrm{C}$ winding temperature limit. thermal resistances selected in this illustration.

\section{CONCLUSIONS AND OBSERVATIONS}

This theoretical feasibility study on the use of HPs in thermal management of electrical machines has shown significant improvement in heat removal from the statorwinding assembly as compared with a more conventional system. Both analysed HP-based system concepts for the enhanced and primary heat transport employed commercially available, off the shelf HPs. The theoretical findings suggest that the overall performance gains in specific output of the electrical machine are limited by the standard HP construction considered here. Custom HP solutions enabling for an improved balance among the stator-winding conductor fill factor, heat transfer rate and additional power loss are more likely to provide better performance improvements. However, this would require a careful consideration from the initial design stage rather than a retrofitting approach adopted in this exploratory work.

The sensitivity analysis of imperfections in thermal contact interfaces within the stator-winding assembly with integrated HPs further confirm that custom HPs, which fully utilise available slot windows might be a better option, e.g. no contact thermal resistance between HG and HP. The other thermal contact interfaces, e.g. winding to $\mathrm{HG}$, core pack to winding and core pack to housing have also an important effect on effectiveness of the analysed heat removal variants. It is evident that the stator-winding fabrication process providing a low thermal contact resistance between the winding body and the heat transport features is a prerequisite to realising a motor design with considerably improved specific output. This is either by assuring increased power loss handling as for S-I VIII and possibly by reduced weight of the mechanical and thermal management parts as for S-II.

As highlighted earlier, the overall heat rate, which the HP is capable of sustaining is predefined by the HP construction including the mechanical space envelope. In this work, operation of the HP has been emulated by an ideal high thermal conductivity equivalent. Such model representation does not account for the HP operating limits, i.e. HP operating point. HPs self-regulate within a specific range of temperate and heat rate. This operating point dependant HP representation is required to fully assess the performance improvements discussed in this work. Clearly, the heat rate for the analysed off the shelf HPs might be insufficient, e.g, when used as a primary heat removal path. This might lead to 'drying out' of the HP, i.e. phase change heat transport is no longer possible, when operating in the high-power loss region. This would require some experimental work, which the authors originally intended, but due to the COVID-19 lockdown have been unable to sufficiently progress. Consequently, the experimental body of work will be presented in the future publications.

\section{ACKNOWLEDGMENT}

The authors wish to thank the Engineering and Physical Sciences Research Council UK for supporting this research.

\section{REFERENCES}

[1] D. A. Reay, P. A. Kew, R. McGlen, Heat Pipes: Theory, Design and Applications, Elsevier, 2013.

[2] A. Faghri, "Heat Pipes: Review Opportunities and Challenges," Frontiers in Heat Pipes, vol. 5, no. 1, pp. 1 - 48, 2014. 
[3] M. Bradford, "The Application of Heat Pipes to Cooling Rotating Electrical Machines," IET International Conference on Electrical Machines and Drives, pp. 145 - 149, 1989.

[4] M. Popescu, D. A. Staton, A. Boglietti, A. Cavagnino, D. Hawkons, J. Goss, "Modern Heat Extraction Systems for Power Traction Machines - A Review," IEEE Transactions on Industry Applications, vol. 52, no. 3, pp. $2167-2175$, May/June 2016.

[5] C. Oshman, B. Shi, C. Li, R. Yang, Y. C. Lee, G. P. Peterson, V. M. Bright, "The Development of Polymer-Based Flat Heat Pipes," IEEE Journal of Microelectromechanical Systems, vol. 20, no. 2, pp. $410-$ 417, April 2011;

[6] D. Jafari, W. W. Wits, B. J. Geurts, "Metal 3D-Printed Wick Structures for Heat Pipe Application: Capillary Performance Analysis," Applied Thermal Engineering, Elsevier, vol. 143, pp. 403 - 414, July 2018.

[7] N. Hack, S. Unz, M. Beckmann, "Ceramic Heat Pipes for High Temperature Applications,” Energy Procedia, Elsevier, vol. 120, pp. 140 - 148, August 2017.

[8] P. Meisel, M. Jobst, W. Lippmann, A. Hurtado, "Design and Manufacture of Ceramic Heat Pipes for High Temperature Applications," Applied Thermal Engineering, vol. 75, pp. $692-699$, January 2015.

[9] Y. Sun, S. Zhang, G. Chen, Y. Tang, F. Liang, "Experimental and Numerical Investigation of Novel Heat Pipe Based Cooling Strategy for Permanent Magnet Synchronous Motor," Applied Thermal Engineering, vol., pp. 1 - 25, January 2020.

[10] A. Tuysuz, F. Meyer, M. Steichen, C. Zwyssing, J. W. Kolar, "Advanced Cooling for High-Speed Electrical Machines," IEEE Transactions on Industry Applications, vol. 53, no. 3, pp. 2077 - 2087, May/June 2017.

[11] M. Bernagozzi, A. Gerogulas, I. Malavasi, N. Miche, M. Marengo, “A Novel Lumped Parameter Model for Loop Heat Pipes - Validation and Parametric Analysis," $15^{\text {th }}$ UK Heat Transfer Conference, pp. $1-2$, September 2017.

[12] M. P. Kukharskii, "Closed Evaporative Cooling of Rotating Electrical Machines," Journal of Engineering Physics, vol. 27, no. 3, pp. $446-$ 456, September 1974.

[13] N. Aprianingsih, A. Winarta, B. Ariantara, N. Putra, "Thermal Performance of Pulsating Heat Pipe on Electric Motor as Cooling
Application," $3^{\text {rd }}$ International Tropical Renamable Energy Conference, pp. 1- 6, 2018.

[14] D. C. Deisenroth, M. Ohadi, "Thermal Management of High-Power Density Electric Motors for Electrification of Aviation and Beyond," Energies, MDPI, vol. 12, no. 19, pp. 1 - 18, September 2019.

[15] N. Putra, B. Ariantara, "Electric Motor Thermal Management System using L-Shaped flat Heat Pipes," Applied Thermal Engineering, Elsevier, vol. 127, pp. 1156 - 1163, February 2017.

[16] M. Bradford, "The Application of Heat Pipes top Cooling Rotating Electrical Machines," $4^{\text {th }}$ International Conference on Electrical Machines and Drives, pp. 145 - 149, 1989.

[17] P. J. Marto, A. S. Wanniarachchi, "Heat Pipe Cooling of Large Electric Motors," Naval Postgraduate School Monterey CA, Progress Report NPS69-88-012PR, pp. 1 - 72, 1988.

[18] C. Tighe, C. Gerada, S. Pickering, "Assessment of Cooling Methods for Increased Power Density in Electrical Machines," XXII International Conference on Electrical Machines, pp. 1-7, 2016.

[19] T. A. Jankowski, Numerical and Experimental Investigations of a Rotating Heat Pipe, PhD thesis, The University of New Mexico, USA, May 2007.

[20] F. Wu, A. M. El-Refaie, "Investigation of an Additively-Manufactured Modular Permanent Magnet Machine for High Specific Power Design," IEEE Energy Conversion Congress and Exposition, pp. 777 784, 2019.

[21] R. Wrobel, A. Hussein, “A Feasibility Study of Additively Manufactured Heat Guides for Enhanced Heat Transfer in Electrical Machines," IEEE Transactions on Industry Applications, vol. 56, no. 1, pp. 205 - 2015, January/February 2020.

[22] https://www.europeanthermodynamics.com/

[23] A. A. El-Nasr, S. M. El-Haggar, Effective Thermal Conductivity of Heat Pipes," Heat and Mass Transfer, Springer-Verlag, no. 32, pp. 97 $-101,1996$.

[24] R. Wrobel, P. H. Mellor, D. Holliday, "Thermal Modelling of a Segmented Stator Winding Design," IEEE Transactions on Industry Applications, vol. 47, no. 5, pp. 2023 - 2030, September/October 2011. 